\title{
A reply to Gomez and Hart's 'goldrush'
}

\author{
KATHERINE CROWLEY (NÉE DONOVAN)*+ AND JOHN R ELLIOTT* \\ *Department of Earth Sciences, University of Oxford, South Parks Road, Oxford OX1 3AN \\ +CAFOD, Romero House, 55 Westminster Bridge Road, London SE1 7JB \\ E-mail: kcrowley@cafod.org.uk
}

This paper was accepted for publication in May 2013

W hen it comes to resilience building, we welcome constructive and cross-regional dialogues between scientists and practitioners. We were disappointed and indeed saddened by the tone of the response by Gomez and Hart (2013) to our invited and time-sensitive reflection (Crowley and Elliott 2012). As a scientist (Elliott) and practitioner (Crowley) pairing we wish to improve relations, understanding and practical applications across all sorts of boundaries. We hope that this response to our commentary will not undermine let alone deter the efforts of applied scientists engaging in interdisciplinary research with practitioners.

We emphatically stand by our conclusion that, 'Wealth, advanced earthquake science, strict building codes and community preparedness have saved thousands of lives in both Japan and New Zealand' ( $p$. 214). Straightforward comparisons of earthquakes of similar magnitude that have struck near cities are testament to this: the shallow magnitude 7 earthquake which occurred near Christchurch in September 2010 killed no one, however the same sized shallow event which occurred near Port-au-Prince, Haiti in January 2010 killed an estimated 50 000-300 000. Similar comparisons can be made between the massive earthquakes and tsunamis associated with the 2011 Tohoku-Oki event and the Indian Ocean tsunami in 2004, in which more than 10 times as many people were killed.

The Fukushima accident resulted in no fatalities from the explosions and initial radiation release. A recently published World Health Organization (WHO 2013) report concludes that for the general population inside and outside of Japan, the predicted risks are low and no observable increase in cancer rates above the baseline rates are anticipated, except for those most nearest the plant in a region much smaller than the Fukushima prefecture. They note that the outcome could have been far worse, with the impact being much smaller than the primary consequences resulting from the earthquake and resulting tsunami.

Gomez and Hart appear to interpret the data shown in their Figure 1 as a 'goldrush'. An alternative inter- pretation is that science is built upon careful data collection, not rhetoric, so that it is not surprising to see an upsurge in publications when major new data sources arise. The scientific understanding that underpins applied Disaster Risk Reduction is founded on the forensic exploration of disaster events; without learning from past disasters there would be no progress in reducing vulnerability and building resilience.

While welcoming the authors' personal reflections on the current state of response in New Zealand and Japan, we would encourage them to think further about how those insights might contribute to applied research, in collaboration with relevant local authorities and communities.

For us, in conclusion, our commentary made the case for the following:

- Those living in developing countries are worst affected by earthquakes, and much can and should be learnt from developed countries who are more resilient.

- As the global need for energy access increases, and given that the majority of the world's population now live in urban areas, it is vital that building codes are appropriate and enforced (as other disasters in places such as Bangladesh continue to attest).

\section{References}

Crowley K and Elliott J R 2012 Earthquake disasters and resilience in the global North: lessons from New Zealand and Japan The Geographical Journal 178 208-15

Gomez C and Hart D E 2013 Disaster gold rushes, sophisms and academic neocolonialism: comments on 'Earthquake disasters and resilience in the global North' The Geographical Journal 179 272-7

WHO 2013 Health risk assessment from the nuclear accident after the 2011 Great East Japan earthquake and tsunami, based on a preliminary dose estimation World Health Organization, Geneva 